\title{
Schellenberg on the Epistemic Force of Experience
}

\author{
Matthew McGrath
}

According to Schellenberg, our perceptual experiences have the epistemic force they do because they are exercises of certain sorts of capacity, namely capacities to discriminate particulars - objects, property-instances and events - in a sensory mode. She calls her account the "capacity view."

In more detail, the view is the following. Because they are exercises of sensory discriminatory capacities, experiences have content properties. In the good case, when they are successful exercises of these capacities, the experience has singular content - content directly about the discriminated particulars in the environment. Experiences with singular content give the subject what Schellenberg calls factive evidence. One has factive evidence only in the good case - when one is genuinely discriminating the particulars one seems to be. However, factive evidence isn't the only sort of evidence experiences provide. They also provide what Schellenberg calls phenomenal evidence. Phenomenal evidence comes from a related but distinct sort of content-property experiences have, again because they are exercises of discriminatory capacities. Phenomenal evidence comes from an experience having a content type. A content type is neither a token singular content nor a general content but a content "schema." As I understand this, to say experiences have content types is to say that they are so structured as to be eligible for having token singular contents, even if they only have gappy contents because no particulars are discriminated. Phenomenal evidence is evidence for a corresponding general proposition, e.g., there is a white cup before $m e$, whereas factive evidence is evidence for a singular proposition, e.g., o is a white cup.

Schellenberg claims that the capacity view makes it possible to give principled defenses of a number of intuitively appealing verdicts about cases prominent in the literature in epistemology on internalism and externalism. Two in particular are noteworthy. First, intuitively in bad cases, e.g., realistic and unsuspected hallucination cases and the more extreme brain-in-a-vat case, it seems the subject is justified in believing the likes of there is a white cup before me. But it also seems, Schellenberg thinks, that in the good case of genuine perception, one is better justified in this same belief. The capacity view can accommodate and defend the correctness of these intuitions. In the bad case, one still has justification, from one's phenomenal evidence, for one's general perceptual beliefs. However, because in the good case one also has factive evidence, one has better justification for these beliefs. Second, 
Swampman is intuitively justified in his perceptual beliefs. Some epistemic externalists are forced to deny Swampman is justified. On the capacity view, Swampman is just as justified as ordinary perceivers are. He exercises the same capacities as they do. Thus, he has both factive and phenomenal evidence.

In this paper, I will raise three concerns about Schellenberg's capacity view. The first is whether we might do better to leave capacities out of our epistemology and take content properties as the fundamental epistemically relevant features of experiences. I argue we would. The second is whether Schellenberg's appeal to factive and phenomenal evidence accommodates the intuitive verdicts about the bad case that she claims it does. I argue it does not. The third is whether Schellenberg's account of factive evidence is adequate to capture nuances concerning the justification for singular but nondemonstrative perceptual beliefs, such as the belief that's $N N$, where NN is a proper name. I argue it is not.

If I am right, these points suggest a mental-state-first account of perceptual justification, rather than a capacity-first account, and one which treats the good and bad cases alike in respect of justification and complicates the relation between perceptual content and what one is justified in believing.

\section{A place for capacities in perceptual epistemology?}

What reasons might we have for thinking exercising perceptual capacities could provide the subject with evidence?

In general, the truth of (1) does not secure the truth of (2):

1. Capacity $\mathrm{C}$ is a capacity to $\mathrm{X}$.

2. So, exercises of capacity $\mathrm{C}$ provide the subject who has the capacity evidence that one $\mathrm{Xs}$, or at least evidence for the truth of some proposition $\mathrm{P}$ suitably related to $\mathrm{X}$-ing.

There are many capacities one might have without knowing it and without knowing one is exercising it. You might have a capacity to please your neighbor with piano playing. When you exercise it, you have no evidence that you are doing so, nor do you have evidence for suitably related propositions such as my neighbor enjoys my playing, my neighbor is pleased, etc. If an instance of (1) is to secure the truth of (2), this must be due to something about the particular X. Perhaps in the case of the capacities 
underlying perceptual experience, we can find a filling for ' $X$ ' on which the truth of (1) does secure the truth of (2) for appropriate corresponding P.

There are two sorts of search-strategy one might use in seeking out the right $\mathrm{X} / \mathrm{P}$ in the case of perception. The first is to seek out a mental state $\mathrm{X}$ with independent epistemic force and to explain the epistemic relevance of capacities to $X$ as derivative from the epistemic force of $X$. Such an approach is capacities-second approach. The second strategy is to choose an X without independent epistemic force and to explain the epistemic relevance of exercises of this capacity as deriving from the fact that they are exercises of this capacity. This is a capacities-first approach. Schellenberg endorses the capacities-first approach. I think there are reasons to prefer the capacities-second approach.

There are as many capacity-second views as there are theories of the epistemic force of experience that take their epistemic force to come from some source other than the capacities exercised in having the experience. I'll focus on perhaps the two most natural theories. The factive states view takes $\mathrm{X}$ to be the factive perceptual state of seeing that $\mathrm{P}$ (in the case of vision). On this view, such states have autonomous epistemic force, and capacities to be in such states have epistemic relevance only because they are capacities to produce states with such epistemic force. The phenomenal states view takes $\mathrm{X}$ to be perceptual experience with certain content. On this view, such states have autonomous epistemic force and, again, capacities to enjoy them have epistemic relevance derivatively. ${ }^{1}$

Schellenberg would quick to point out that these views have trouble with cases from the epistemological literature on internalism and externalism. The phenomenal states view does not explain how one is epistemically better off in the good case - not merely in respect of knowledge but evidence and justification. On the phenomenal states view, the BIV, for instance, gains the same justification from his experience as you do. (I deny this is an advantage, but I'll not challenge it here.) The factive states view does not explain how the BIV's experiences have epistemic force. The BIV, after all, does not successfully exercise the capacity to see that $\mathrm{P}$.

We might revise these views to mitigate these problems. In the case of the factive states proposal, we might allow that unsuccessful exercises of capacities to see that $\mathrm{P}$, too, can give one evidence, insofar as they make it seem to the subject that she sees that P. On this view, similar to ones of

\footnotetext{
1 These two views are simplified versions of those of McDowell (1994) and Pryor (2000).
} 
certain disjunctivists, the state of seeing that $\mathrm{P}$ is epistemically fundamental and the state of seeming to see that $\mathrm{P}$ has epistemic force insofar as the subject in it seems to be in the epistemically fundamental state. This is still a capacities-second view. What is epistemically fundamental are states of seeing that $\mathrm{P}$. They have epistemic force by their nature, and not because they are exercises of capacities. States of seeming to see that $\mathrm{P}$ have epistemic force derivatively, but their epistemic force comes not from capacities but from the fact that they are states of seeming to be in a state which has epistemic force.

The phenomenal states view that we have described treats the good and bad cases alike. But there are variations on this view that treat them differently. Consider this variation. In the good case, one has a phenomenal state with a singular content, a content directly about the perceived object; whereas in the bad case, one's phenomenal state has a content type, a type that in the good case allows the experience to have singular content. We then say that phenomenal states with singular content have epistemic force with respect to their contents and that phenomenal states with the corresponding content type have epistemic force only with respect to a generalized version of that same content. Let's call this revised phenomenal states view the $t w o$ tiered phenomenal states view.

Now, this view looks a lot like Schellenberg's. However, it is a capacities-second view. On this view, it's having phenomenal states with the relevant contents and content types that is doing the epistemic work. However you get a phenomenal state with either a singular content or the corresponding content type, it's because you have the phenomenal state with that content or content type that you have the perceptual evidence you do. It's consistent with the two-tiered phenomenal states view that your phenomenal states have the contents or content types they do because they are exercises of certain capacities. That is, capacities might enter into the metaphysical ground of our having these phenomenal states. Still, capacities are not themselves epistemic explainers; rather, they enable us to enjoy the phenomenal states that are the epistemic explainers.

We have arrived at a capacities-second view nearly identical to Schellenberg's. It delivers the very same verdicts on cases as Schellenberg's does. Indeed, as far as I can see, the only difference between this two-tiered phenomenal states capacities-second view and Schellenberg's capacity-first view is that the latter adds a layer of metaphysical grounding and asserts this metaphysical grounding to be epistemically explanatory as well. Schellenberg's view, that is, adds that the phenomenal states have the contents they do because they are exercises of the relevant discriminatory 
capacities and it asserts that this is what gives these states their epistemic force.

My question is why we need to take this extra step. Why does your experience as of a white cup justify you in believing of the cup that it is white? The first-stab answer is: because it is an experience having the singular content concerning that cup that it is white. ${ }^{2}$ The question is why this first stab wouldn't be the end of the epistemic story, as far as facts about the experience are concerned. Why would we need to add to the explanation metaphysically deeper facts about the experience?

Compare an analogy from value theory. The fact that an event is an instance of suffering suffices to make it prima facie disvaluable. Now, do we need to go deeper into the metaphysical nature of suffering to give a deeper value-theoretic grounding of the disvalue of the suffering? I don't see why. Perhaps any suffering is an instance of suffering because it has some complex neurobiological property N. Still, even though the event of suffering is a case of suffering because it is an instance of $\mathrm{N}$, what explains its disvalue is that it is a case of suffering, not that it is a case of $\mathrm{N}$. Similarly, we could say that it's simply because the experience has a certain content that it has a certain epistemic force. Yes, it might have that content in virtue of further facts, but what explains its epistemic force is its having that content, not the further facts. ${ }^{3}$

Moreover, if we do take the extra step, we face the question of how it is that the facts about the capacities exercised are epistemic explainers. I cannot find an answer to this question in Schellenberg's paper. She is explicit that experiences have their epistemic force because they are exercises of discriminatory capacities, but I cannot find an argument for this view as against the capacities-second two-tiered phenomenal states view we have been considering.

There are ways Schellenberg could give capacities an explanatory role. The two such answers I will discuss are both epistemically externalist. That is, they make the possession of evidence or justification dependent on

2 This may not be what Schellenberg takes the content of this experience to be. However Schellenberg understands that content, we could reformulate the answer accordingly.

${ }^{3}$ Generally, we would deny the following principle: if $x$ having P1 metaphysically grounds $\mathrm{x}$ having $\mathrm{P} 2$ and $\mathrm{x}$ having $\mathrm{P} 2$ makes it the case that $\mathrm{x}$ has epistemic property $\mathrm{Q}$, then $\mathrm{x}$ having $\mathrm{P} 1$ makes it the case that $\mathrm{x}$ has epistemic property $\mathrm{Q}$. Schellenberg herself denies the principle, since she allows that the fact that an experience is an exercise of a capacity might itself have a deeper metaphysical grounding but also claims that this deeper grounding is explanatorily relevant to epistemology. 
truth-related factors that can vary across subjects who are alike in respect of their mental states as traditionally conceived. ${ }^{4}$

The first is a reliabilist proposal. Suppose it were true that having the capacity to discriminate particulars entailed that exercises of it were usually successful. We might then explain why exercises of the capacity to discriminate blue should give me this evidence: generally, when I exercise the capacity, I succeed in discriminating blue, and therefore generally when I exercise the capacity, it is true that there is something blue before me; and if generally when $\mathrm{Y}$ obtains, $\mathrm{X}$ obtains, then $\mathrm{Y}$ is evidence of $\mathrm{X}$; and therefore exercising the capacity is evidence of something blue being before me.

There is not much to like about this account. Having the capacity to discriminate blue does not seem entail general success at doing so, for one thing. I might have the capacity to discriminate blue but in fact generally discriminate white with blue lights shining on it. And of course a BIV might have the capacity to discriminate blue physical objects without ever doing so because she never visually discriminates any physical object. The account also requires giving the intuitively unappealing verdict about the BIV case: the BIV's experiences do not justify her in believing (or provide her evidence) that there is something blue before her.

The second is broadly Burgean. ${ }^{5}$ At times in the paper, Schellenberg appeals to ideas with a Burgean flavor: perceptual capacities have a function and they have the epistemic import they do in part because of that function. They are also "systematically linked" to the good case. Here is the Burge-inspired account, in rough outlines. One has the capacity to discriminate blue, if one does, because of past causal interactions between one's own and one's ancestors' mental states and instances of blue. (If I and my ancestors would have interacted with some other color in place of blue, I would not have had the capacity to discriminate blue but rather to discriminate that other color.) Now, why do my present exercises of this capacity give me evidence of something blue being before me? Because in conditions that are normal with respect to my capacity - i.e., in the conditions that obtained during the relevant past interactions with blue, the interactions that make it the case that my capacity is a capacity to discriminate blue - the relevant mental states were caused by instances of blue. Thus, my current exercises of the capacity to visually discriminate blue are evidence that something blue is before me because in the sorts of

\footnotetext{
${ }^{4}$ On traditional conceptions of mental states, a lifelong brain in a vat (or Swampman) could have the same mental states that I in fact have.

5 See Burge (2003).
} 
conditions which ground my having this capacity the relevant mental states were caused by something blue. Unlike the previous proposal, it is not reliability that grounds epistemic force but reliability in conditions explanatory of one's having the capacity.

This Burge-inspired account is not as easily refuted as the simple reliabilist account. There are important questions, I think, about why it is that if I am in non-normal conditions I am entitled to believe there is something blue before me when I exercise my capacity to discriminate blue - why should the fact that such a belief would be reliably formed in normal conditions show that there is something epistemically favorable about it when formed in non-normal conditions?

The main problem, though, is that this account, like the reliabilist one, restricts the verdicts one can give about cases. On this account, one has the capacity to discriminate blue only because of one's own and one's ancestors' past causal interactions with blue. However, Swampman had no past interactions with anything and lacks ancestors. Thus, if Schellenberg is to give the intuitive response to the Swampman case, the one she gives - that his experiences do give him evidence concerning his environment - she cannot accept this Burgean proposal.

By contrast, the capacities-second account does not restrict one's verdicts about cases in these ways. And this seems right. ${ }^{6}$

Let me summarize the main points of this section. We can fashion a capacities-second account that agrees with Schellenberg on all the cases and is just like Schellenberg's with the exception that it does not attribute any epistemic significance to whatever it is that metaphysically grounds facts about experiences having the content properties they do. As far as I can see, this account, the two-tiered phenomenal states view, has all the advantages of Schellenberg claims for her capacities-first view. Moreover, Schellenberg's own account seems incomplete without an account of how facts about capacities are epistemic explainers. The two most natural such accounts are epistemically externalist and therefore restrict in undesirable ways the verdicts she can give about the relevant cases. Schellenberg's view thus seems to take on a burden that buys one no advantages but saddles one with several important disadvantages.

\footnotetext{
6 This is not to deny that it might turn out that some externalist account of experiential content is correct, in which case the lifelong BIV might well not have experiences with contents as of blue, with the result that the intuitive verdict that the BIV is justified in believing something blue before him would be false. However, epistemology alone shouldn't decide this. Only epistemology together with metaphysical theories of content does so.
} 


\section{Good and bad cases.}

As we've noted, one of the advantages Schellenberg claims for her account is that it respects both internalist and externalist intuitions about cases. One externalist intuition is that Percy (who perceives a white cup) is in an evidentially better position than Hallie (who hallucinates a white cup). Schellenberg claims her account can accommodate this purported evidential superiority.

Schellenberg's explanation is as follows. Phenomenal evidence, the evidence guaranteed by the fact that one is exercising a perceptual capacity, whether successfully or not, only supports general beliefs, whereas factive evidence, the evidence one has over and above phenomenal evidence when one successfully exercises the same capacities, supports singular beliefs as well. Thus, more of Percy's beliefs are justified - his singular beliefs are justified while Hallie's aren't. But Percy's general belief, too, is better justified, because Percy has more evidence for it - he has the evidence from his singular belief whereas Hallie doesn't. ${ }^{7}$

In my view, this treatment of Percy and Hallie underestimates the epistemological credentials of Hallie's beliefs, both her singular and her general beliefs. Schellenberg acknowledges that Hallie does indeed have a singular belief, even if the content of that belief is gappy. Hallie expresses a belief when she declares, "that is a white cup." Now, is that belief justified? I think it is very hard to answer no. The same intuitions that push us toward thinking Hallie is justified in the general belief push us toward thinking Hallie is justified in the singular belief as well. Yet for Schellenberg Hallie's singular belief isn't justified, because there is no evidence for it, no factive and no phenomenal evidence. ${ }^{8}$ Perhaps Schellenberg will simply take this in stride: "fine, no justification for Hallie's singular beliefs." But there is a second problem in the offing.

Hallie's general belief seems to depend for its justification on her singular belief being justified. If Hallie were to ask herself why she thinks there is a white cup before him, she would answer, "because that thing is a

${ }^{7}$ Here Schellenberg relies on the assumption that "having more evidence for $p$ means that $p$ is better justified" (p. 7).

${ }^{8}$ As Susanna Siegel pointed out to me, a question arises here for Schellenberg: why couldn't enjoying an experience with a certain content type make Hallie justified in her singular belief? Perhaps she doesn't have factive evidence, but could her phenomenal evidence justify her singular belief? 
white cup." Her general belief seems based on her singular belief. If we rely on the standard proper-basing requirement on doxastic justification, then we must conclude that Hallie's general belief is justified only if and because her singular belief is. If Schellenberg has to declare the singular belief unjustified, she seems forced to declare Hallie's general belief unjustified as well. Perhaps Hallie has propositional justification for her general belief, but the belief itself, because based on an unjustified belief, is doxastically unjustified. This is an unfortunate result. ${ }^{9}$

\section{Singular perceptual content and the nuances of justification}

Schellenberg writes that factive evidence is "individuated by the token content that ensues from employing these capacities successfully in a particular environment." Because the experiences constituted by successful employment of these capacities have singular token content, factive evidence, too, is singular. So far, so good. But what follows about justification?

About the case of identical twins, Schellenberg writes:

"The token content of the perceiver's mental state will differ, depending on what particular she is perceptually related to. On the capacity view, the token content counterfactually varies with the world. So what factive evidence one has is counterfactually sensitive to the world to which one is perceptually related. In W1 with object $\alpha$, we have content $\mathrm{C} 1$. If the world changes to $\mathrm{W} 2$ with object $\beta$, we have distinct content $\mathrm{C} 2$, however close $\mathrm{W} 1$ and $\mathrm{W} 2$ are. What evidence one has determines what one has justification to believe. So I am arguing that even though we cannot tell whether we are seeing [twin] $\alpha$ and not [twin] $\beta$, we have (unbeknownst to us) evidence for the presence of $\alpha$ when seeing $\alpha$ and so prima facie justification for the proposition that $\alpha$ is present."

The justification is prima facie only, and so we needn't worry that her account will give the incorrect verdict that even if I know I can't tell the twins apart then if I see $\alpha$ I know I it is $\alpha$.

Still, the underlying principle here seems overly strong. The principle

\footnotetext{
9 The same considerations apply to the capacities-second two-tiered phenomenal states view outlined in the previous section, for it, too, denies that Hallie has evidence for her singular perceptual belief.
} 
is this:

If the object $\alpha$ enters into the token content of one's experience, then one is prima facie justified in believing that $\alpha$ is present.

Suppose I happen to see a man on the street. He happens to be Bob Edwards, the former NPR host. Am I prima facie justified in believing it is Bob Edwards? No, and not because I have a special defeater. I have no idea what Bob Edwards looks like. Looking at him, there is no prima facie support from my experience for Bob Edward is present that is overridden or defeated. This is not to say that I lack justification for believing other propositions about the person I see. I am justified in believing that this man is present or this man is tall, etc. when I see Bob Edwards.

Something similar applies to properties. The principle:

If the property F-ness enters into the token content of my experience, then I am prima facie justified in believing $\mathrm{F}$ is present.

Someone without perfect pitch may hear what is in fact a middle $\mathrm{C}$. The property of being a $\mathrm{C}$ pitch enters the token content of the person's experience. Still, the person has no prima facie justification to believe a $\mathrm{C}$ pitch is present. The person doesn't know a $C$ from a $D$ from an $A$. There is no prima facie evidence that is somehow defeated or overridden. Again, there is justification to believe other propositions: this pitch is present or this pitch is neither high nor low.

If factive evidence is individuated by token experiential content, then the link between factive evidence and prima facie justification must be more complex than Schellenberg seems to allow. ${ }^{10}$

\section{References}

Burge, Tyler (2003). "Perceptual Entitlement." Philosophy and Phenomenological Research 67(3): 503-548.

McDowell, John (1994). Mind and World. Cambridge, MA: Harvard University Press.

10 Thanks to James Genone and Susanna Siegel for helpful comments. 
Pryor, James (2000). “The Skeptic and the Dogmatist," Nous 34(4): 517549.

Schellenberg, Susanna (2015). "Phenomenal Evidence and Factive Evidence" Philosophical Studies (this issue). 